Amazonía Peruana, Tomo XI, № 20. 1991: pp. 65 - 86

\title{
La Regionalizacion
}

\section{En La Perspectiva De Las}

\section{RELACIONES INTERNACIONALES}

\section{De La Amazonia}

Oscar Paredes Pando

La regionalización, desde sus inicios, ha sido tema polénico. El análisis de $\mathrm{Pa}$ redes Pando se preocupa del rol de las regiones con respecto a la politica externa puesto que, por ejemplo, cotidianamente se establecen relaciones con los paises vecinos en diversos pueblos fronterizos de nuestro pais.

Regionalization, since its beginnings, is a centroversial topic. The analysis that Paredes Pando makes is worried about the role that Regions have respect the external policy, since, for example, daily relations are commonly established with the neighboring countries in different boarder towns of our country.

Die Regionalisierung war von Anfang an ein umstrittenes Thema .Die Untersuchung vor: Paredes Pando befasst sich mit der Rolle der Regionen in Zusammenhang mit der Aussenpolitik, da ja z. B. die Grenzbewohner unseres Landes täglich mit Bewolnern der Nachbarländer Verbindung aufnehmen. 


\section{INTRODUCCION}

Las particularidades propias que presentan algunas de las Regiones, nos motivan de manera especial, reflexionar sobre el rol de éstas en un asunto de gran trascendencia en el desarrollo nacional, cual es, la Política Externa, elemento básico de las relaciones internacionales; de manera, por ejemplo, es diferente la responsabilidad Regional-Nacional en el contexto amazónico o altiplánico, por decir de la Región Amazonas o José Carlos Mariátegui frente a las Regiones Andres A. Cáceres o Arequipa.

Tal vez, el Poder y Gobierno Central, consideren "demasiada" aspiración que las regiones asuman algunas de las tareas en el sistema internacional, sobre todo en lo concerniente al diseño, formulación e implementación de Políticas Externas, pero la realidad, nos demuestra que existe una práctica constante en estos menesteres, desde que la presencia de fronteras genera interdependencia y relación entre países vecinos.

Las características de nuestra Amazonía, en términos de colindar con naciones de menor o mayor desarrollo económico relativo, también sugieren pensar, en la necesidad de asignar e implementar a las futuras regiones de elementos o mecanismos que constituyan la base para ingresar gradualmente en el quehacer externo, y con ello lograr y conseguir capacidad de respuesta en términos de armonizar los intereses nacionales a partir de las aspiraciones regionales.

Un proceso de regionalización -por lo menos a nivel normativo-, no puede soslayar en contexto internacional, de ahr, la necesidad de reflexionar al respecto, y sobre todo, tomando en consideración, que los aspectos de políticas externas en nuestro país responden a prácticas típicamente burocráticas. Por consiguiente, este hecho, amerita detenerse en todo este intento de reajustar la estructura y funcionamiento del Estado, en la perspectiva de democratizar las acciones y decisiones del gobierno. 
Consideramos, oportuno alcanzar para su debate algunas ideas a mnnera de hipótesis de trabajo, las cuales, puedan ser analizadas en el "I Seminario de Investigaciones Sociales en la Amazonía", donde esperamos obtener mucha más motivación para este intento de estudio e investigación.

\section{INTERDEPENDENCIA Y YRONTERAS EN LA CUESTION EXTERNA}

La interdependencia, es una característica fundamental del sistema internacional, donde sus componentes: Unidades Políticas, se encuentran o ingresan a una probabilidad de alteración, debido a los cambios que ocurren en los demás, como consecuencia de una mutua necesidad, por cuanto la autarquía cada vez va quedando en el recuerdo.

Referente a este asunto, Deutsch (1), se hace la siguiente pregunta; ¿Hasta qué punto los gobiernos y pueblos de cualquier Estado-Nación, pueden decidir su propio futuro, y hasta que punto el resultado de las acciones depende de las condiciones y acontecimientos fuera de sus fronteras?

En un intento explicativo, podemos señalar, que en principio, el Estado se caracteriza por su soberanía, esto es, su jurísdicción excluyente sobre determinado territorio y por el monopolio del poder coercitivo legítimo o no sobre sus habitantes. 'Este concepto, recoge los aspectos esenciales: el derecho y la fuerza-poder (2), que a nivel de abstracción supone que todos los Estados-Nación deben poseer igual poder, igual derecho, aunque en el plano de la realidad concreta, la tendencia es, de desigualdad, de soberanía y de mala distribución del poder.

Las Unidades Políticas, como núcleos de acción de la política internacional, independientemente del nivel de desarrollo socio-económico alcanzado por cada uno de ellos, van participando activamente del 
escenario internacional, a pésar de que en muchos casos no "contasen" con el poder, ello, especialmente entre los países del tercer mundo (3).

Independientemente de su fuerza, muchos países subsisten ejem.Paraguay, Bolivia y Ecuador en Sudamérica, o de Honduras en Centroamérica-, y siguen constituyendo la forma dominante de organización de los pueblos, y el vehículo para su expresión internacional, pues, sería dificultoso concebir sociedades carentes de organizacion política yque sin capacidad de acción y decisión puedan lograr entablar relaciones con otras Unidades. Muy a pesar de la situación de los países indicados, ellos participan en las mismas condiciones, dada su situación de países soberanos, en los diferentes esquemas de integración, tales como el Grupo Andino, el Tratado de Cooperación Amazónica, Tratado de la Cuenca del Plata, Mercado Común Centroamericano, etc.

El desarrollo de nuestros países en la región amazónica, por diversos factores, ha generado desigualdades entre los Estados, desigualdades que han propiciado relaciones asimétricas entre estas Unidades Políticas, panorama que caracteriza las relaciones internacionales, y sobre el cual, pareciera existir una consagración estructural de tal desigualdad, de ahí, que existen "preferencias" en las relaciones de unos con otros, por ejemplo de Brasil con o hacia Bolivia y Ecuador. Aún en estas condiciones los Estados continúan siendo los agentes fundamentales de las interdependencias existentes.

La consolidación de los Estados, vía la integración interna sobre la articulación de regiones, hace de éstas Unidades irreductibles, y que por su soberanía, actúan y deciden sobre las colectividades que congregan a su interior; en consecuencia, no pueden ser situados en un bloque homogéneo, por las disparidades de desarrollo regional y las diferencias internacionales de poder, dando como resultado relaciones de diferentes niveles: entre iguales, entre competidores, o entre adversarios, e inclusive entre desiguales, todos ellos con un denominador común: el problema de Poder, elemento central en las relaciones entre palses, traducido muy objetivamente en la situación de las zonas fronterizas. Al respecto, Morgenthau (4), señala: "A semejanza de las demás políticas, la política internacional es una lucha por el poder, cualesquiera que sean sus objetivos finales, es el poder siempre objetivo inmediato y mediato" $(+)$. 
A pesar, de la cada vez mayor relación entre determinadas áreas fronterizas, y consecuentemente de los Estados, éstos se mantienen como Unidades Políticas soberanas, que en el mayor de los casos, tratan de mostrarse como extremadamente resistentes, inclusive en condiciones favorables o mejor dicho desfavorables que afectan en grado mayor su autonomía.

El proyecto de Regionalización, con la creación de Gobiernos Regionales, modifica la estructura del Estado, en consecuencia, el asunto del poder tendrá alguna alteración, en la perspectiva de ser compartido por otras instancias, por lo que, tanto en el concepto Estado y Gobierno, incorporarán el principio de poder regional, inclusive el Derecho hará lo propio, aunque en este último caso será restringido por los mismos alcances de la ley de Bases de Regionalización: "Las leyes regionales se remiten al Presidente de la República para su promulgación y publicación, quien las promulga, observa o veta" (Art. 47); en consecuencia, dadas estas características, importa afirmar, que en el contexto de las interdependencias inclusive de orden regional, la cuestión del poder parecierá ser decisiva.

¿Sobre quién se ejerce el Poder Nacional?, si aceptamos que los Estados-Nación de la Amazonía tienen soberanía sobre sus jurisdicciones, es sobre estos ámbitos que se ejerce tal poder, y sólo puede rebasar sus jurisdicciones formales -fronteras- cuando logran tener algún grado de influencia, hecho que se evidencia principalmente, en las relaciones desiguales, por ejemplo de Brasil con los demás países, como resultado, esta nación extrapola su área de poder mas allá de sus límites territoriales, alterando las posibilidades de una interdependencia horizontal con una tendencia cada vez más desigual, hecho que tiene incidencia en cuestiones internas y externas. En estas circunstancias, ¿cómo puede mantenerse la soberanía llámese de Bolivia o Surimán, especialmente en sus decisiones de naturaleza externa? ¿Será posible en estas condiciones implementar políticas externas independientes? ¿Es viable proponer alternativas de desarrollo para las Regiones Amazónicas, Ucayali o Inka, a espaldas de sus implicancias en el vecino país, o más propiamente, preguntémonos, si las acciones del gobierno vecino; Brasil, no inciden en nuestras actuales Regiones o Sub-Regiones Amazónicas? 
Estas y algunas otras inquietudes pueden ser respondidas a partir de algunas hipótesis -consideradas por algunos estudiosos o especialistas como "modelos teóricos"-, tales como la Cuestión Sistémica, que considera el sistema internacional, responsable de amoldar gran parte del comportamiento exterior de los países, en consecuencia, unas regiones son más sensibles a su entorno externo que otras, por lo que su comportamiento puede ser una especie de simple reacción a estímulos que se dan a partir de tal sistema internacional. Otra hipótesis, es la Política del Poder, donde las capacidades o atributos nacionales del Estado, son factores dominantes, hecho que facilita en alguna medida la autonomía en la decisión, tal vez en esta instancia se puede ubicar al Brasil, especialmente durante la gestión de los gobiernos militares a partir del Presidente Castelo Branco, o, en el caso de Venezuela, durante la crisis energética de los años setenta, que gracias a su gran potencial de hidrocarburos va logrando un sitial en el palco internacional.

Finalmente, otro elemento explicativo, constituye el asunto de la dependencia, por cuanto la posición de la región en el sistema económico internácional, bien como las lazos históricamente establecidos en las estructuras internas y externas, condicionan en gran parte los procesos económicos y políticos que tienen lugar en las sociedades latinoamericanas y aún del tercer mundo (5).

Al tomar a las Unidades Políticas, como células del sistema internacional amazónico, observamos que en la totalidad de los ámbitos las relaciones fronterizas, son condición necesaria y suficiente para que esa relación pueda ser calificada como "Internacional".

Dadas las particularidades existentes, las fronteras amazónicas, pueden ser consideradas como economías regionales, con relativo aislamiento de los centros dinámicos de decisión nacionales, sean éstos $\mathrm{Li}$ ma, Bogotá, Caracas o Brasilia y La Paz. Sus posibilidades de desarrollo se ven reducidas por tales circunstancias, además de la ausencia de políticas específicas de promoción, son pués, ámbitos donde convergen dos economías con políticas propias, en ocasiones diferenciadas, de modo tal que generan movimientos de bienes, servicios y personas en procura de aprovechar las distintas oportunidades que dicha particularidad confiere a uno u otro ámbito. 
En las áreas fronterizas se hace más evidente el escaso y desigual desarrollo económico-social en relación con otras zonas, así como carecen de instituciones idóneas, carecen también de poder, para adoptar o prömover decisiones que impulsen las actividades locales; sus recursos naturales son insuficientemente explotados e incluso poco conocidos, en su mayoría sin vías de comunicación, y en muchos casos son de similar conformación humana -especialmente de minorías étnicas- y geográfica; en ocasiones con raíces comunes de historia, todas sujetas a efectos de políticas definidas desde los gobiernos centrales, cuyas modificaciones muchas veces obstaculizan la continuidad de las relaciones que hubieran podido establecer con comunidades vecinas, y emplazadas en puntos geográficos que las tornan objeto de eventuales fricciones e inclusive de conflictos con el país colindante.

La caracterización señalada líneas arriba, permite asignar una especificidad a la problemática de las áreas de frontera que revelan dificultades en acciones de cooperación tanto en su contexto nacional como en la zona contigua del país vecino.

Como ya señąamos, la interdependencia se refiere a la situación en que áreas vecinas de países con frontera común se interrelacionan, circunstancia que contiene el elemento central: Area de interrelación, cuyo carácter y comprensión permiten definir los alcances de la cooperación fronteriza, y sobre el cual la primera responsabilidad corresponderá a los gobiernos regionales, dada la especificidad de cada zona, y de donde se derivarán las propuestas para acciones bilaterales o multilaterales con los países vecinos.

En la región amazónica, así como en cualquier otra región, frontera, hace referencia a un límite que separa dos o más jurisdiccioness políticas en cada una de las cuales tienen vigencia leyes, normas y hasta idiomas que son propios de los países que entran en contacto en estos puntos. Las políticas económicas aplicadas a cada lado de. la frontera, los recursos disponibles, y otros aspectos diferenciadores, son los componentes de las fuerzas impulsoras de aquel relacionamiento y a la vez marcan las cosas circunstanciales de su potencial intensidad.

La interdependencia, complementación o cooperación en lo económico, la asistencia en lo social, y el emprendimiento de actividades conjuntas en cualquier ámbito de interés, señalan un amplio campo a 
las posibilidades de interacción, cuyos límites están delineados por las restricciones establecidas al movimiento de personas y bienes y por el tipo de relaciones internacionales que los países involucrados establecen con el resto del mundo y con sus vecinos en particular.

El criterio que establece o define la extensión de una región de interdependencia fronteriza: Putumayo, Yavari, Purús, Iberia-Iñapari, Heath, etc., reside en los alcances de interacción económica o social verificada entre las regiones vecinas, especialmente cuando estas o aquellas regiones no se encuentran comprendidas en algún instrumento que formalice tal situación, ya que si este fuera el caso, se hallaría delimitada en el acuerdo que establece.

De esta manera, la dimensión de la región de interdependencia, determina importantes diferencias en la calidad del vínculo y en el potencial de la interacción. Desde los centros de servicios fronterizos que admiten entendimientos y acciones relativas a la que eficiencia de los que allí se prestan, hasta las regiones sean definidas por la geografía o las jurisdicciones políticas, en las que se puedan establecer programas de estudios, explotación, comercialización, cooperación en materia de servicios sociales, entre otros, se aprecian diversos niveles de interacción, con una diversidad de posibilidades y un interés proporcional al tamaño y los elementos o factores que configuren la región de interdependencia.

No obstante, resulta necesario establecer un límite a la extensión de esa región, dado que la ampliación sucesiva del concepto "región de interacción", podría conducir a considerar un territorio nacional completo, he aquí el quid del asunto: "interés nacional", por cuanto, al tener idea clara de este hecho estamos más próximos a diferenciar una región de interdependencia de un espacio de dimensión nacional. Sin duda alguna, la interdependencia y relación fronteriza, están orientadas a conseguir determinados objetivos económicos, sociales y/o políticos, entre ellos, el desarrollo económico, movilización de recursos, mejora de las condiciones de vida y sobre todo solidaridad, así como disminución del carácter conflictivo de la línea de frontera, todo ello constituirán lineamientos permanentes en el accionar del gobierno nacional, en tanto, que serán políticas constantes en la gestión regional. 
Los alcances de la cooperación amazónica, constituyen un esquema típico en el asunto de la interdependencia fronteriza, por cuanto independientemente de cualquier otra intención, ésta, no deja de constituir un mecanismo de integración-cooperación, donde por las características de los Estados-Nación concurrentes, se hace evidente la cuestión de países de mayor, mediano y menor desarrollo económico relativo, quedando comprendido en el primero Brasil, en el siguiente, Venezuela, Colombia y Perú, finalmente Guyana, Surimán, Ecuador y Bolivia respectivamente.

Entre estos grupos o jerarquías de niveles de desarrollo, el problema fundametal, se da con los denominados países de menor desarrollo económico relativo, cuyas regiones, tales como el Oriente peruano evidencian diferencias sustanciales con los vecinos, siendo los casos más resaltantes la desigualdad en cuanto a niveles de desarrollo de las regiones peruanas de Amazonás y Ucayali así como de la SubRegión Madre de Dios, frente a los Estados Federales brasileros de Amazonas y el Acre. Trátase del Mercado Común Centroamericano, Grupo Andino, Cuenca del Plata, etc, los problemas que se plantean como consecuencia de áreas de menor desarrollo económico relativo, representan un serio obstáculo para los programas de cooperación-integración, esto se evidencia mucho más, cuando los ámbitos geográficos de frontera política son considerados -a pesar de su importancia nacional- como zonas marginales, de extremo atraso y tenue desarrollo, hechos que se dan especialmente en los ámbitos amazónicos de Bolivia, Perú, Ecuador, Colombia y aún Venezuela.

Relievar la situación de menor desarrollo de zonas fronterizas, si bien deriva generalmente en espectativas, puede también, motivar a pensar en la necesidad de otorgar una decidida atención a dichos ámbitos en el quehacer de los gobiernos regionales, de esta manera, se trata de un problema real que no puede soslayarse.

Como su nombre indica, los ámbitos regionales de menor desarrollo, se caracterizan por un menor grado de desarrollo y una menor dimensión de mercado interno, lo que es posible identificar a partir de algunos indicadores que permitan clasificar y/o determinar cuales son las regiones de menor desarrollo y cuales no son (6). 
En lo concerniente a la cuenca amazónica, las áréas del Beni, Pando, Madre de Dios en Bolivia y Perú respectivamente, así como Amazonas, Vaupés, Guainia en Colombia, e inclusive el territorio de Amazonas en Venezuela, son las jurisdicciones más postergadas, hecho que continuará aún en el largo plazo, por cuanto no existe mínima intención ni menos la voluntad de los gobiernos centrales de otorgar atención prioritaria en la perspectiva de implementar de infraestructura, dotar de recursos, invertir significativamente, para, a partir de ahi, motivar su participación en las instancias decisorias vinculadas a cuestiones externas de política.

La presencia de regiones de menor desarrollo -especialmente los casos de Madre de Dios y Pando- expresan una disparidad sustancial, por ejemplo, frente al Estado brasilero de Acre y desniveles marcados, que inclusive puede ocasionar situaciones conflictivas, debido a que, si bien los esquemas de integración o cooperación ofrecen nuevas oportunidades también propician riesgos y peligros, pérdida de la identidad nacional, tendencias al desmembramiento o anexión a paísés vecinus, etc. Por su debilidad, las regiones de menor desarrollo, están propensas a incurrir en estos riesgos, habiéndose presentado casos como en las localidades fronterizas de Iberia, Iñapari, etc., donde elementos culturales del vecino país son cada vez más notorios, pero sobre todo influyentes.

La menor capacidad de estos ámbitos para aprovechar las nuevas oportunidades que se presentan en los esquemas de integración-cooperación, también se ve agravada por la excesiva centralización de las decisiones de todo lo concerniente a cuestiones de política externa, exclusivas a las Cancillerías y a los propios instrumentos de política internacional, por cuanto, muchas veces se plantean propuestas muy generales, que a su vez genera esperanzas demasiado globales, dejando de lado aspectos puntuales que muchas veces se traducen en propuestas planteadas por las propias poblaciones (7), a partir de sus necesidades más sentidas.

No diferenciar el problema de la distribución equitativa de los beneficios y costos en la participación de los programas de cooperación de cualquier proyecto o propuesta de política internacional, también constituye factor decisivo en postergar la participación de los ámbitos directamente involucrados en los esquemas de desarrollo multinacionales; 
este hecho se ha debido a que las actuales relaciones entre países se enrumban por el "pragmatismo", esto es, lograr y obtener alguna ventaja o rédito, que por lo general se traduce en actividades económico-comerciales y a partir de ello en conseguir algo de influencia, que es sinó nimo de Poder y Fuerza en el sistema internacional, algo que de por sí niega la voluntad de una interdependencia horizontal.

\section{FUNDAMENTO NORMATIVO Y OPCION REGIONAL EN POLITICA EXTERNA}

La Constitución Política del Estado define que el gobierno peruano es unitario, representativo y descentralizado, conceptos que a lo largo de la historia republicana han venido repitiéndose, excepción hecha de la expresión "descentralizado" incluída sólo en nuestra Carta Magna en 1979, y que oficialmente se define en los términos siguientes "...consiste en la transferencia de funciones y la correspondiente facultad de decisión en los aspectos políticos, económicos, administrativos del centro a la periferie" (8).

La opción presidencialista de gobierno, a pesar de la existencia y funcionamiento de un estilo parlamentarista, hace, que el Jefe del Ejecutivo, centralice un conjunto de atribuciones, entre otros, "dirigir la política exterior y las relaciones internacionales", para lo que indudablemente cuenta con un aparato que por su función, organización, gestión, administración y normatividad implementa un estilo de "Política Burocrática" (9), como veremos más adelante.

Dentro de la transferencia de funciones que debe aplicar el gobierno central, también el-Poder Ejecutivo trata de hacer lo propio, por tanto "delega algo" de su competencia, pero que "supone siempre subordinación a la legislación las materias que alteran el carácter unitario de la República, el ordenamiento jurídico del Estado o que pueden ser opuestos al interés nacional o.al de otras regiones" (10). Por otra parte, las cuestiones de interdependencia y cooperación, también son previstas en nuestra Constitución, que señala, que el país promueve la inte- 
gración económica, política, social y cultural de los pueblos de latinoamérica, para lo que da prioridad a estos tratados sobre los demás compromisos multilaterales.

Concordante con la Constitución Política, el Plan Nacional de Regionalización, señala que entre otros propósitos permanentes del desarrollo del pars, está garantizar la presencia del Perú a nivel latinoamericano y mundial, a través de una activa participación en los procesos de integración y en la consecución de un nuevo orden económico internacional.

La intención de participar de los procesos de integración y/o cooperación, no constituyen simples aspiraciones idealistas, sino, que éstas se encaminan a lograr un lugar en el escenario internacional, hecho que está en relación directa al poderío logrado por una nación o a una opción què sea diferente al sistema, aspectos que se fundamentan en el nivel de desarrollo socioeconómico alcanzado por un país. Es sobre esta base que se impulsa un determinado Estado-Nación en materia de política externa.

No hay duda, que el Estado continúa siendo instrumento privilegiado de las relaciones internacionales, es por ese mismo hecho que debe horizontalizar las decisiones, y no exclusivizar a un aparato central y burocrático, situación que es evidente en el Perú,a pesar de las tibias intenciones de descentralizar. De esta manera, dentro de la administración regional, si bien está permitido impulsar un conjunto de acciones; éstas no deben "rebasar" otras que son sin duda monopolio del gobierno central, así, en el Plan Nacional de Regionalización, se ha llegado al extremo de explicitar "...no están comprendidas las actividades de aquelos Ministerios que cumplen funciones de Defensa, Orden Interno $Y$ Relaciones Exteriores", alcance bastante contradictorio cuando el mismo dispositivo indica, entre otros criterios para la delimitación regional el aspecto de la Seguridad y Geopolítica, elementos básicos de la Defensa, que en los tiempos actuales han dejado de ser concepto eminentemente militar, por cuanto, incorpora a todos los segmentos de la sociedad, tal como señalan los mismos textos de Defénsa Nacional, elaborados por el CAEM.

Las relaciones entre Estados, son pues relaciones internacionales, de esta manera el fenómeno estatal continúa y continuará como ele- 
mento constitutivo del sistema internacional; en consecuencia, un país como el nuestro débilmente integrado y con un gobierno excesivamente centralista, deberá buscar los mecanismos que permitan hacer extensivas las decisiones y sobre todo, comprometan a las instancias regionales como forma de garantizar la efectivización de compromisos que surgen en todos los esquemas de integración y cooperación. Lo señalado se confirma por circunstancias dadas en la región, tales como:

- Se constata, que en la Amazonía o ámbito de influencia, el número de Estados tienden a multiplicarse, tal vez, sobre el impulso continuo de una corriente nacionalista, como en los casos de la independencia de los Estados de Guyana y Surimán, y posiblemente continuará lo propio con la Guayana Francesa, a esta situación, se puede adicionar el comportamiento de las dirigencias de las colectividades políticas que tienen como medio a su disposición para obtener los "privilegios de la soberanía", consagrar su existencia como Estados-Nación e ingresar al contexto internacional;

- Fracaso de todas las tentativas de internacionalización aplicadas en la región, tratándo de someter a la autoridad directa de un organismo central-internacional. Al respecto, valga la ocasión para recordar los proyectos de Hudson Institute, o la Hilea Amazónica, impulsados desde Norteamérica y Europa respectivamente, con la finalidad de internacionalizar la Amazonía, como si se tratase de territorios de nadie.

Ampliar la gestión internacional hacia los gobiernos regionales del futuro, permitirá sin duda, otorgar un mejor tratamiento al conjunto de intercambios públicos y privados que se desenvuelven fundamentalmente sobre las fronteras, de manera particular en la Amazonía Peruana dada su amplitud; por cuanto, relaciones internacionales de una manera simple para el caso que venimos estudiando y para muchos otros, no significan otra cosa que el conjunto de transacciones o flujos que atraviesan las fronteras, o apenas tienden a atravesar, o si se prefiere, puede ser también entendido así; "las relaciones internacionales, pueden ser definidas no en términos de fronteras que las envuelven, pero sí, en términos de fronteras que las trasgreden"(11).

Con estos alcances, llegamos a comprender que las relaciones y las perspectivas internacionales en las regiones, se basan en hechos 
concretos, independientemente de su magnitud, pueden ir desde el intercambio de alimentos básicos entre pobladores de una $u$ otra frontera, hasta la sofisticada teoría de las relaciones internacionales y desarrollo regional que se alcanza en centros especializados de formación académica. De esta manera, no hay duda, que en la "cuestión externa" concurren acciones públicas y privadas, pero siempre llevando en cuenta el elemento fundamental, cual es la estructura del mundo en Estados-Nación desde luego sin dejar de lado la interdependencia entre unos y otros y que a su vez inciden inclusive en políticas públicas internas, todo ello finalmente en dirección de la universalización de las relaciones.

Finalmente podemos señalar, que no existe elemento normativo alguno que posibilite a los gobiernos regionales tener acceso a las decisiones en aspectos de política externa, por cuanto la propia Ley de Bases de Regionalización es bastante clara al señalar "El Gobierno Regional, es competente para,...ejercer el derecho de iniciativa en la formulacion de Leyes y Resoluciones Legislativas en materias que le son propias". Vale recordar, que seguin el Plan Nacional de Regionalización las funciones referentes a defensa, Orden Interno y Relaciones Exteriores, no están comprendidas en las funciones de los gobiernos regionales, aunque la posibilidad se daría por el lado de intercambio fronterizo que señala el art. 70 de la Ley 24650 ,Inc.ñ.

\section{PRACTICA BUROCRATICA EN LAS RELACIONES INTERNACIONALES}

Tal vez, para entender mejor este asunto, sea necesario dar algún brevísimo alcance sobre la cuestión burocrática, o más propiamente el asunto de la burocracia; y con riesgo de resumir excesivamente podemos señalar que la burocracia es una organización formal con las características de criterio jerárquico de autoridad y comunicación, con relacionamientos especificos entre superior yisubordinado, entre jefe y 
dependiente, entre funcionario y empleado, entre "alta dirección" y " órganos de línea", apoyo, etc; con un "lenguaje particular" con especialización no sólo respecto al desempeño sino también en lo que se refiere a la función con una aparente y compleja división de actividades $y$, finalmente con un conjunto de acciones, operaciones internas conducidas mediante una serie de procedimientos que atribuyen énfasis especial a reglas formales, directivas, instructivos, etc.

En todo Estado, independientemente del régimen político, el Jefe del Ejecutivo-Presidente de la República, actúa en el ámbito de un contexto político-burocrático, sin duda, sujeto a características específicas que difieren de un país a otro, y en esas condiciones, 'los procedimientos burocráticos también difieren. En tànto este asunto se dé y las modalidades de formulación política sean en cierta forma diferentes, la tendencia general, casi en todos los paises, es de contar con una burocracia "razonablemente" necesaria.

El présidencialismo en el Perú, ha propiciado que la concentración de un excesivo número de decisiones sean tomadas por una persona: Jefe de Estado, y que por lo tanto, exige de una organización compleja experimentada o no, cuya finalidad o función es asesorar al responsable del Ejecutivo, en la implementación de una cada vez "mejor política externa". La asesoría burocrática, tiene por finalidad ejecutar la política más acertada y refleja por tanto la necesidad de especialización y experiencia en la conducción de asuntos intęrnacionales y garantizar la obtención, interpretación y transmisión de informaciones. Supone tamibién, que ella se destina a garantizar un cierto grado de estabilidad y regularidad en el proceso de formulación de la política.

El primer punto a recordar es que merced a la Ley Orgánica del Ministerio de Relaciones Exteriores, así como a la propia Constitución, las decisiones que envuelven políticas externas son tomadas de acuerdo con ciertos procedimientos considerados padrones de gestión establecidos antelademente al surgimiento de una determinada situación. Este estilo de procedimiento, corta o anula toda posibilidad futura de iniciativa que pudiera tener su origen en los gobiernos regionales, directamente beneficiados o afectados con una determinada decisión, dada su situación fronteriza. 
Como indicamos, la estructura del gobierno central, caracterizado por el "presidencialismo", contribuye a una concentración de atribuciones en el Ejecutivo, donde el Ministerio de Relaciones Exteriores es "...Organo del Estado, a través del cual el Presidente de la República dirige la política exterior", en consecuencia, le corresponde exclusivamente a este ministerio, "...formular, conducir y evaluar la política exterior", actuando como órgano de gestión del Estado en asuntos internacionales.

No hay duda que el Ministerio de Relaciones Exteriores, es la entidad especializada y responsable en asuntos de política internacional, y con las excepciones establecidas por la Ley del Servicio Diplomático, la totalidad de las responsabilidades son atendidas o desempeñadas por funcionarios de carrera, quedando el personal clasificado en tres niveles; Diplomático, Técnico-Administrativo y Auxiliar; por todas estas características, esta entidad no siempre está comprendida en la administración pública en su conjunto. ¿Quién es Diplomático en el Perú?

La Organización del Ministerio de Relaciones Exteriores, adicionada a las múltiples tareas especializadas, dan como resultado una compleja estructura, que trae consigo la gran dificultad que surge frecuentemente en el sistema burocrático, de introducir iniciativas o innovaciones, por.cuanto, tiene primacia la tendencia de toma de decisiones que sean consideradas "seguras" y consecuentemete estén de acuerdo con los procedimientos conocidos, y que no prescriben mayor riesgo o pueden significar divergencia en relación a las reglas ya conocidas; esta práctica, envuelve tal vez la totalidad de actividades e incorpora a todos los escalones burocráticos $y$, posiblemente, constituya el mecanismo de resistencia contra todo intento de "delegar" funciones a otras instancias en aspectos de política exterior', consecuentemente, se consolida cada vez más exclusivizar toda responsabilidad que tenga implicancia internacional en la Cancillería.

¿Quién o quienes toman iniciativa en la formulación de políticas externas? Si bien, tal cual señala la Constitución Política del Estado, el Presidente de la República, es el que dirige la política exterior, las iniciativas tienen diversos origenes, pueden ser una persona o personas, pero que en el fondo constituyen grupos de intereses, las iniciativas no responden a momentos de lucidez de un funcionario, éste, es expresión de intereses, el diseño de las políticas externas, también responde a es- 
ta característica; primará el "interés nacional" centralista desde luego en contra de la aspiración regional, para esto, ya se tiene el argumento aún constitucional de "velar por la unidad del Estado-Nación, finalidad que consideramos algo objetivo y no meramente enunciativo. La infinidad de factores que contribuyen al afinamiento de las iniciativas para aspectos externos, tienden a jugar rol protagónico de acuerdo a la circunstancias, por cuanto aún estamos lejos de precisar que existen politicas externas de largo plazo, hecho común en latinoamérica -excepción hecha de Brasil, Venezuela y México-. De esta manera, es que en "un momento" resulta prioritario el Grupo Andino, en otro SELA, y aún el Pacto Amazónico; variación de opciones que podrá tener otro comportamiento cuando se incorpore el Interés Regional, que por lo general es más permanente o constante, frente a las decisiones nacionales. Así, reiteramos que será necesario articular lo regional con lo nacional y a la inversa, donde no pueda ser punto de partida y llegada la cuestión del "interés nacional" si es que éste no se define, y continúa en térninos abstractos.

Adicionado a los factores que inciden en las propuestas o formulaciones de políticas externas se encuentra la excesiva jerarquización del aparato público, que lleva a un hecho incómodo, cual es una larga espera en tangibilizar alguna propuesta. De ahí, es sugerente la organización menos compleja en la administración responsable de las cuestiones externas, por cuanto, este mecanismo, sólo conduce a buscar "esclarecimientos" cada vez más engorrosos, que finalmente derivan en anular muchas veces iniciativas de las instancias representativas de poblaciones vinculadas e interesadas a la solución de problemas comunes que por lo general se dan en zonas de frontera.

Lo señalado hasta este punto, no debe hacernos pensar o aceptar que las decisiones en política externa "son simples decisiones", esto sería ilusorio, porque en realidad, su formulación es resultado o producto de muchas otras decisiones intermedias, que emergen y pasan por un proceso de interacción a lo largo del tiempo; esta característica, puede justamente ser condición para ir incorporando gradualmente a los Gobiernos Regionales en la formulación de políticas externas, por cuanto, las ideas e informaciones que fluyen al proceso se originan en una variedad de fuentes oficiales o privadas, cuyas acciones son ejecutadas por personas en varios niveles de las diversas organizaciones, siendo 
que la información es transmitida y comunicada posterior y jerárquicamente a otras personas portadoras de autoridad para decidir.

La puesta en práctica del procedimiento antes señalado, partiendo aún de los pequeños centros poblados, especialmente fronterizos, llegando al nivel regional y posteriormente al nacional, puede significar el inicio de un proceso de democratización de las políticas externas, por cuanto a su vez, la decisión, producto de un proceso volverá a los verdaderos interesados en determinadas políticas; como tal, gran parte de su ejecución estará garantizada y comprometida con los actores directos de las políticas externas: la sociedad. Con este mecanismo, se podrá inclusive alterar la decisión pre-existente del formulador de una determinada política, que muchas veces, es resultado de una elucubración teórica o consecuencia de negociaciones burocráticas y de esta manera la acción de la Cancillería incorporará a todos los elementos que participan en el proceso formulador de la política, de manera, que tampoco habrá un renunciamiento de sus funciones o responsabilidades, tan sólo se logrará algo importante, cual es incorporar a todos los actores de la sociedad en asuntos de política' externa, evitando la fragmentación de las decisiones y sobre todo, dejando de lado actitudes verticales que constituyen expresión de gestión y administración pública antidemocrática colindando con el autoritarismo.

A la "especialidad" del sector Relaciones Exteriores, en el quehacer internacional, se puede sumar otro hecho, que también incide en retener cualquier posibilidad de ampliar la voluntad de decisión en asuntos de política externa a los futuros gobiernos regionales, nos referimos al clásico concepto de "seguridad nacional", que vinculándola a la idea de supervivencia misma del Estado, surge una interesante pregunta formulada por García-Bedoya: ¿Cómo asegurar la supervivencia misma del Estado mediante determinados vínculos de mecanismos internacionales, la preservación de las fronteras, la relación con los vecinos, el establecimiento de alianzas, la neutralización de los conflictos y todo aquello que constituye un sistema de seguridad dirigido por una diplomacia? (12). Desde luego apegarse al concepto de "seguridad" trae consigo entender este hecho en términos de defensa, consecuentemente "sustentado" en instituciones militares, cuyas tareas no están comprendidas en la tarea de los gobiernos regionales. 
La clásica idea de la seguridad, ha sido tratada desde siglos atrás, por cuanto, si bien el Estado-Nación, representa un conjunto de exi-. gencias, las cuales deben ser atendidas, y una de ellas es la referente a la continuidad y/o permanencia, por lo tanto, pareciera constituir el primer objetivo de un Estado-Nación, en el contexto internacional; según Thomas Hobbes "toda unidad política quiere sobrevivir, gobernantes y gobernados desean de cualquier modo mantener su colectividad por todos los tiempos" (13). Y por su carácter de autónomo y soberano de éstas Unidades, cada una de ellas toma las decisiones más convenientes, en términos de lograr su garantía, protección y consecuentemente su seguridad.

A partir de este hecho se alcanza o se llega al concepto de "Defensa", expresión que frecuentemente es confundida e identificada con el rol de las instituciones militares y exacerbado en coyunturas de fuertes tensiones sociales, trayendo consigo la identificación entre Defensa y Fuerzas Armadas, en consecuencia se antagoniza la sociedad civil del Estado. Consideramos, que esta manera de entender o comprender el fenómeno de la Seguridad y Defensa hacen que se derive muy simplistamente en la cuestión del "Gobierno Unitario" enarbolado por la Constitución Política y que pone taxativas a la gestión regional en aspectos de seguridad y garantía que también requieren ser replanteados.

En los tiempos actuales, la Seguridad del país es conocida con la expresión "Seguridad Nacional", la nuisma que tiene claras connotaciones ideológicas, que posterior a la segunda guerra mundial fue "elevada" a una especie de valor supremo "difícil" de interpretarla con realismo, del cual se habla todo el tiempo y que no necesita explicarla,"por cuanto, ella -la seguridad nacional-es anterior a toda reflexión o análisis, es una propuesta de la cual las instancias del poder se inspiran por cuanto la "seguridad nacional es la primera y última palabra".

En un esfuerzo de explicar la significación de Seguridad, el CAEM indica: "El concepto Seguridad, comporta una noción de garantía, protección o tranquilidad frente a las amenazas o acciones adversas a la propia persona, a las instituciones 0 a bienes esenciales, existentes o pretendidos", posiblemente el CAEM, se proyecta a un tipo ideal de sociedad y Estado ajeno al presente, pero sea cual fuese la intención, el hecho es, que la cuestión de la Seguridad constituye elemento fundamental en la acción externa del Estado-Nación. 
Como señalaba Carlos García-Bedoya, al lado de esta gran área de la política externa -la seguridad- de un Estado, "...existe otra que es lo que se llama la independencia misma: es decir, cómo asegurar a un Estado el máximo margen de autonomía en las decisiones que este Estado debe tomar en función de sus intereses,..., o sea, qué es lo que un país tiene que hacer más allá de sus fronteras para afianzar que sus propias decisiones tengan el marco de la autonomía necesaria para responder en función a sus propios intereses y que no estén supeditados o dominados por intereses que le son ajenos" (14). Todo este alcance sin duda, puede ser respondido a partir de la problemática del desarrollo económico y social de los países, que cada vez buscan mayor interdependencia para no ser dependientes y en este contexto se sitúan las acciones de carácter bilateral, como relaciones de un Estado con otro Estado, las multilaterales, cuando los Estados se reúnen en ámbitos mucho más amplios y de intereses comunes; y finalmente aún otra, que no significa confrontación o deslinde de intereses, sino, que se busca una convergencia de propósitos.

Consideramos que cualquiera de estos mecanismos deben posibilitar una real participación de los entes regionales, por cuanto, en acciones bilaterales o multilaterales tienen gran responsabilidad en su ejecución e implementación, asị podemos afirmar, que las regiones de la Amazonía están fuertemente vinculadas a los compromisos y responsabilidades del Tratado de Cooperación Amazónica, que regiones costeras, en tanto que por ejemplo todo el país tiene responsabilidad en el GRAN, SELA, ALADI, etc, de ahí que no podemos dejar de lado el aspecto de la perspectiva internacional en el proceso de regionalización, o el rol que asumirán algunas regiones en el escenario internacional dadas las características particulares del Perú. 


\section{NOTAS}

(1). Karl Deustch. Analise das Relacoes Internacionais. Un B.1982.

(2). "Fuerza", entendida como una estimativa de los recursos humanos y materiales, que pueden ser utilizados para inferir el grado de suceso que una nación necesita alcanzar.

"Poder" entendido, como la capacidad de una Unidad Política: País, de imponer su voluntad sobre los demás (R. Aron). Paz e Guerra entre as Nacoes. UnB.1985.

(3). Ronaldo Sardenberg. Acao e Interacao dos Estados. UnB.1983

(4). Cf.R.L. Wendzel, Relacoes Internacionais. UnB.1985.

$(+)$. En la versión leninista, el Poder, se hace presente aparentemente por encima de la sociedad, y es el llamado a amortiguar el conflicto dentro de los límites del "orden", esta presencia se da como resultado de los antagonismos de las clases con intereses económicos en pugna (V.I. Lenin. El Estado y la Revolución).

(5). Alberto Van Klaveren, en un interesante artículo analiza con más detenimiento este asunto. "Analise das Políticas Externas Latino-americanas: Perspectivas Teóricas" (A América Latina e/a Política Mundial. Edit. Heraldo Muñoz e Joseph S. Talchon. Sao Paulo, Brasil 1986).

(6). Para determinar concretamente las regiones de menor desarrollo relativo, tal vez sea posible tomar en cuenta las propuestas de Moncada y que son, PIB por habitante, proporción del PIB generad w por los principales sectores de la producción, proporción de la PEA dedicada a las principales actividades productivas, distribución de la población urbana y rural, formación bruta de capital, exportaciones e importaciones, etc., (Moncada José. INTAL, 1969); asimismo son bastante sugerentes las propuestas de Palomino Roedel, Acuerdo de Cartagena y el Trato preferencial en favor de Bolivia y Ecuador. 1962.

(7). En 1981, las poblaciones fronterizas de Puerto Maldonado, del Perú y Riberalta de Bolivia, suscribieron importantísimos acuerdos de apoyo y cooperâción en la perspectiva de solucionar múltiples problemas co- 
munes, tales como la mejora de embarcaderos, dregado del río, apoyo en acciones de salud preventiva, abastecimiento alimentario y otros que significaba solucionar sus problemas inmediatos, los cuales no son atendidos porque aún no han sido "aprobados por las respectivas Cancillerías".

(8). Plan Nacional de Regionalización, Ley No. 23878.

(9). Robert L. Wendzel. Relacoes Internacionais. 1985.

(10). Constitución Política del Estado. Art. 266.

(11). Rosenbaum, Noami. Readings on the international Political System. York University.

(12). Carlos Garcia-Bedoya. Política Exterior Peruana; Teoría y Práctica. Lima, 1981.

(13). Thomas Hobbes. Leviatan.

(14). Carlos García Bedoya. Op.Cit. p.78. 